\title{
AS EXPRESSÕES DA COMIDA NO FILME “AMARELO MANGA”
}

\section{Expressions of Food on Film “Amarelo Manga”}

\section{RITA DE CASSIA GILI}

(UNIP, Brasil)

\begin{abstract}
Resumo
Este estudo procurou analisar a relação entre o cinema e a simbologia da comida, pois o alimento não está restrito apenas ao seu valor nutricional, ele abarca culturas, símbolos e sociabilidades. Esta relação será feita por meio da exploração do longa-metragem "Amarelo Manga", lançado em 2003 e dirigido pelo pernambucano Cláudio Assis. Pode-se concluir que as expressões da comida analisadas nas cenas do filme envolvem os sentidos do prazer e sociabilidade. A comida associada à sexualidade gera satisfação. A antropofagia adultera a personalidade. E o abate de um boi simbolizou a degradação dos valores humanos. O ponto central da análise deste trabalho esteve na importância da carne, que permeou todas das expressões debatidas. Hora como alimento, hora como símbolo de Poder, sexo, e canibalismo. E por fim, a carne do boi abatido pôde levar a reflexão sobre a violência que o animal sofre antes de se tornar um alimento cotidiano. Procurou-se contribuir com o debate acerca da ciência da antropologia alimentar no campo das ciências humanas e sociais, associando esta discussão ao cinema como ferramenta de veiculação de cultura.
\end{abstract}

Palavras-chave: comida | simbologia | antropologia | Amarelo Manga.

\section{Abstract}

This study sought to examine the relationship between cinema and the symbolism of food, because the food is not restricted to its nutritional value, it embraces cultures, symbols and sociability. This relationship will be made by exploiting the feature film "Amarelo Manga", released in 2003 and directed by Pernambuco Claudio Assis. It can be concluded that the terms of the food analyzed in the scenes of the film involve the senses of pleasure and sociability. The food associated with sexuality generates satisfaction. Cannibalism adulterous personality. And the slaughter of an ox symbolized the degradation of human values. The central point of the analysis of this study was the importance of the flesh that permeated all of the expressions discussed. Time for food, time as a symbol of power, sex, and cannibalism. Finally, the meat of the slaughtered ox could lead to reflection on the violence that animal suffer before becoming an everyday food. Sought to contribute to the debate about the science of food anthropology in the field of human and social sciences, linking this thread to the movies as a tool serving culture. 
Keywords: Food | Symbolism | Anthropology | Amarelo Manga.

\section{Introdução}

O cinema atua como uma forma de ciência social dentro do campo da arte, expressando afetos e percepções peculiares ao objeto ou a ideia construída. A vida do cidadão comum é cada vez mais invadida pelas imagens e exposição em que o espaço dominado é caracterizado como uma área demarcada onde o indivíduo ou o grupo exerce o poder dentro da sociedade (BORGES, 2011).

O cinema explora e age como agente divulgador de assuntos relacionados à comida, como Festa de Babette (1987), Chocolate (2000), Sem Reservas (2007), o brasileiro Estômago (2007), entre outros (BETTIOL e DIESEL, 2011). Para Borges (2011), o imaginário apresentado pelo cinema é aceito pelo espectador, permitindo acompanhar sua mensagem na totalidade de sua dimensão. As paisagens passam uma mensagem significativa dentro da proposta do cinema. Metáforas são utilizadas como linha interpretativa, sugerindo novas percepções ao imaginário, provocando o pensamento do espectador.

Nascimento (2007) constatou que o cinema explora o simbolismo dos alimentos. O "Encouraçado Potemkim" (1925), do diretor russo Serguei Eisenstein, simbolizou a decadência do regime político por meio de um pedaço de carne podre. A manteiga foi utilizada por Bernardo Bertolucci em "Ultimo Tango em Paris" (1972), e os morangos em "9 1/2 Semanas de Amor" (1986) de Adrian Lyne, simbolizaram o erotismo em antológicas cenas do cinema.

O filme italiano "A Comilança" (1973), dirigido por Marco Ferreri, põe em xeque o limite ao gozo, entre contravenções em que o sujeito habita o espaço da cultura. Os personagens buscam o prazer entre os dois aspectos mais comuns e requintados da cultura: a comida e o sexo, buscando nos exageros a forma de abrandar a infelicidade (CARNEIRO, 2003).

Para Rojas (2009) Glauber Rocha em suas obras desenvolveu uma linguagem cinematográfica inusitada para a época, expondo o espectador à "violência social" aguçando os sentidos e as reflexões. Inspirado em Serguei Eisenstein, cuja teoria definia a utilização de símbolos para transmitir a 
mensagem, Glauber Rocha revelou que "a mais nobre manifestação da fome é a violência".

Várias são as simbologias envolvendo o ato de oomer. O avarento é simbolizado pelo pão duro, o desejo por algo se diz ter água na boca, inverdades são ditas da boca pra fora, e comer do bom e do melhor demonstra riqueza. Também há a associação entre o ato sexual e ao ato de "comer". Mulheres podem ser "comidas", prática aceita pela sociedade apenas após o cerimonial do casamento. A mulher da rua implica a indigestão ao homem, sobretudo por sua provocação à moral e bons costumes impostos pela sociedade (DaMATTA, 1986).

Este estudo procurou analisar a relação entre o cinema e a simbologia da comida, pois o alimento não está restrito apenas ao seu valor nutricional, ele abarca culturas, símbolos e sociabilidades. Esta relação será feita por meio da exploração do longa-metragem "Amarelo Manga", lançado em 2003 e dirigido pelo pernambucano Cláudio Assis.

\section{O filme "Amarelo Manga"}

Dentre os filmes referidos no seminário "Cinema e Comida" que abordou os temas cultura e alimentação, realizado no SESC Vila Mariana-SP em 2006, destacou-se "Amarelo Manga" (2003), dirigido por Cláudio Assis, filmado na cidade do Recife. Sua montagem transmite informações intrigantes, simbolizando a relação entre sexualidade e a comida como satisfação plena do ser humano (COELHO, 2006).

Santos (2010) destacou a distorção dos valores morais da sociedade, apontando o capitalismo como origem da especulação das atividades humanas. Cláudio Assis construiu em "Amarelo Manga" uma história com personagens enigmáticos e situações corriqueiras, œm histórias misturadas, indigestas, e nada convencionais.

Lira (2012) referiu-se ao "Amarelo Manga" sob o enfoque da quebra da centralidade da figura humana, como representação da decadência urbana do terceiro mundo, desafiando o espectador a refletir sobre o paradoxo entre explicar e explicitar a denúncia da verdade vivida pelos personagens. 
A estratégia de denúncia social radical apresentada em Amarelo Manga levou-o a ser considerado um dos filmes mais chocantes da cinematografia brasileira, mostrando o revezamento em meio ao poder e hierarquia entre pessoas da mesma classe social, sendo estes pobres e excluídos. Tal temática foi motivo de estranhamento entre o público brasileiro, acostumado ao modelo norte-americano de otimismo e happy end que construiu uma narrativa eficiente para divulgação de ideologia voltada aos interesses das classes dominantes (SANTOS, 2010).

A fonte documental foi montada em sessenta e sete sequências ao longo de cento e um minutos de exibição. Destaca-se neste estudo a discussão de dez cenas, buscando classificar e explicar as simbologias e significados propostos.

O filme mostra o coloquial suburbano que ocorre em apenas um dia, que verdadeiramente é o mesmo dia de ontem e será o de amanhã. Vários recursos são utilizados para dar velocidade à trama. Como exemplo, uma rádio popular permeia a história em várias ocasiões, situando o espectador e dando ritmo ao passar das horas, revelando em sua programação situações corriqueiras em tempo real.

No transcorrer do longa o diretor lança mão de recursos fílmicos, assim como Glauber Rocha, inspirado no legado do cineasta russo Serguei Eisenstein que considerava que a mágica cinematográfica implica na qualidade da projeção da imagem, utilizando o plano como base de sustentação da montagem e metáforas, envolvendo e provocando as sensações no espectador (GONZAGA FILHO, 2011).

Amarelo Manga contou com várias tomadas de câmera em plongée (visão vertical, de cima para baixo) denotando a invasão de privacidade, revelando certa promiscuidade que minimiza a figura humana, tornando-a simples assessório ou ser inanimado, em que não há barreiras entre o reservado e o evidente, privilegiando a visão crítica do espectador. Cenas em segundo plano demonstram uma visão do lado de fora que procura o personagem dentro do espaço. Narrativas em off onde o personagem faz um monólogo que penetra a história, confessando ao público o seu pensamento.

A trama se passa entre quatro locaçoes principais: o hotel, o matadouro, o bar e a igreja. 
O hotel denominado de "Texas" faz irônica alusão ao ardente estado do sul dos Estados Unidos comparado ao quente sertão nordestino. Sua fachada é suja, os cômodos e corredores são imundos, demonstrando completa deterioração. Os hóspedes são praticamente moradores que passam seu tempo misturados à decadência do local. O abatedouro, onde os animais são sacrificados e os corpos dos trabalhadores se misturam aos pedaços de carne, perpetrando a presença humana inexistente (LIRA, 2012).

A igreja católica mostra-se vazia e em ruínas, transformando-se em um lembrete da fragilidade das promessas de redenção e ressurreição. Em contrapartida há a comparação entre os cultos da igreja Universal resultando na representação de uma igreja alienadora das massas, localizada em uma favela, um ambiente sabidamente, necessitado de assistência (LIRA, 2012).

O gênero cinematográfico a que pertence Amarelo Manga não é bem definido, contudo seu resultado ganhou corpo com formas teatrais, remotas e contemporâneas, imprimindo altivez e integração visual às cenas (ROLAND, 2008).

Para Lira (2012) o Bar Avenida desafia a distinção entre o público e o privado. Também é um lugar de trânsito, personagens vêm e vão, alguns fregueses são cativos do local, passam horas de seus dias bebendo, comendo, e conjecturando. A disposição das mesas admite que as conversas sejam ouvidas por todos, de tal forma que os personagens, algumas vezes a contragosto, acabam por interagir de maneira que assuntos privados se tornam públicos.

Todos os personagens são intrigantes e ligados de algum modo. A mal humorada e mal amada Ligia (Leona Cavalli) é dona do Bar Avenida e mora em nos fundos do estabelecimento. Lúcia Cristina (Kika) (Dira Paes) é uma mulher religiosa frequentadora de cultos evangélicos, casada oom Welington (Chico Diaz) o açougueiro, apelidado de canibal. Dunga (Matheus Nachtergaele), cozinheiro do Hotel Texas é homossexual e apaixonado por Welington. Isaac (Jonas Block) é um hóspede do hotel, dono de um carro amarelo e necrófilo, morbidamente seduzido por cadáveres, chamados por ele de "presuntos", trazidos do IML por Rabecão, funcionário público de comportamento antiético e imoral. O Padre (J ones Melo), e Dayse (Magdale Alves), camelô e amante de Wellington (SANTOS, 2010). 


\title{
3. Expressões da comida destacadas em Amarelo Manga.
}

Amarelo Manga destrói preconceitos delineando paralelos entre libido e religião, sexo e culpa, moral e instinto sexual, dúvida e fé, amor e traição. A desordem dos personagens, então ficcionais, se torna complexa, assim como a vida real do cidadão comum brasileiro. Percebe-se que a intenção do filme é mostrar o apodrecimento da manga (ALVES NETO, 2007).

\subsection{Expressão dos sentidos pela comida, como o prazer, deleite e exultação.}

\author{
Sequência 21 - O Almoço do Canibal \\ (Sala da casa de Kika - int. - dia - cor - som direto) \\ Sentados a mesa, Kika e Wellington almoçam. Ele devora ferozmente sua \\ refeição, engolindo grandes pedaços de carne mal passada, acompanhada por \\ feijão, arroz, farinha e uma manga. Kika come umas rodelas mal cortadas de \\ tomate, duas folhas de alface, arroz e uma batata cozida. Sua expressão é de uma \\ depressão abusada. Não existe vontade de ingestão...
}

“Comer junto" não é a mesma coisa que puramente comer e beber. O valor funcional está subjugado ao social perante o ato de alimentar-se. A comunicação evoca o sentido durante a refeição conjunta quando a comida é determinada por sua agradável convivência (MONTANARI, 2008).

A mesa provoca encontros entre confissões e sociabilidade, podendo-se destacar o amor, a amizade, o poder, entre outros. Quando pequenos comemos junto com a família, reunimo-nos em festas e comemorações. Questões de amor e negócio também são discutidas no momento da refeição, quando decisões podem ser tomadas (NASCIMENTO, 2007).

Esta sequência demonstra que o casal compartilha a refeição, porém evidenciam comportamentos antagônicos, demonstrado pela própria composição de seus pratos. Enquanto Wellington Canibal devora sua refeição, alimentando-se simplesmente por questões biológicas, falando impropérios e malfadando a vida alheia, como que sua vida fosse um exemplo a ser seguido. Kika demonstra sua infelicidade entre rodelas de tomates mal cortadas, 
repreendendo e discordando das atitudes do marido. A convivência neste caso deixou de ser saboreada, indicando a intransigência e o tédio.

\section{Sequência 22 - O Povo Almoça}

(Várias locações - int./ ext. - dia - cor - som direto)

Essa sequência mostra o almoço pela cidade. Almoço familiar, almoço em restaurante, almoço de mendigo, almoço de marmita. A sequência é sempre entrecortada por planos da cidade no meio do dia...

A comida possui atribuição significativa com o passar do tempo. Sua preparação está fortemente vinculada à escolha do alimento a partir da época. Comida de verão, de inverno, de natal, de páscoa, entre outras comemorações. A partir de Hipócrates os médicos passaram a orientar sobre a importância de comer e beber alimentos quentes no inverno e frios no verão. Na "calendarização" da comida, a cultura precede os aspectos naturais (MONTANARI, 2008).

A sensibilidade gastronômica advém de manifestações sociais, em que o ato de comer socializa e está intrinsecamente ligado ao costume e conduta social, marcando época. A alimentação conquistou definitivamente o seu lugar na História. O sentido de comer tornou-se tão admirável quanto o que se come (SANTOS, 2005).

Para Galisa et al (2007) a distribuição energética diária deve ser fracionada e realizada entre as principais refeições: café da manhã, almoço, lanches (manhã, tarde, e noite) e jantar. O aporte energético ideal para cada refeição deve estar devidamente distribuído, a fim de evitar aporte intenso em uma determinada refeição, que prejudica o correto funcionamento do organismo. Para o café da manhã deve-se ingerir entre 20 a $25 \%$ do valor energético total diário, para os lanches, 5\%, para o almoço entre 35 a 40\%, e para o jantar, entre 15 a $25 \%$.

Curiosamente às 12:00 horas, chega-se exatamente a metade de um dia, consolidando o momento que devemos realizar o maior aporte energético calórico. A hora do almoço é um marcador cotidiano. Costuma-se marcar compromissos antes, durante ou após o almoço. Trata-se de um divisor de águas.

\subsection{Expressão da sexualidade como satisfação plena do ser humano}


Sequência 09 - O Coração de Dunga

(Cozinha do Texas Hotel- int. - dia - cor - som direto)

A cozinha é escura, amontoada de coisas mais ou menos organizadas: tentativa de uma ordem frustrada. Wellington entra em quadro e Dunga parece aguardá-lo com muita ansiedade. Ele tem uma expressão abusada, e a boca quase lateral, num esquisito muxoxo.

Dunga (ansioso): Salve Wellington! Chegue mais eu e deixe a carne aqui no balcão.

Wellington (desconfiado): Diz Dunguinha!

Wellington vai até um balcão e deixa o pacote de carne, mas sempre vigiando Dunga com o canto do olho.

Dunga (com falsa preocupação): Que foi, Wellington? Tá me estranhando?

Wellington: Com tu por perto é melhor andar com cuidado. A toda hora tu pode de dar o bote...

O cozinheiro Dunga é apaixonado por Wellington. Seu desejo é conquistar a atração sexual e amor do aģougueiro (LIRA, 2012).

A comida está associada ao cerebral, ao afetuoso e ao sensual. Os sentidos são aguçados pelo cheiro e pelo gosto, induzindo a satisfação plena do ser humano (DaMATTA, 1986).

A carne vermelha representa a afirmação dentro de uma hierarquia social. Quanto mais importante é a pessoa, maior é sua preferência pela carne vermelha. Estes consumidores perœebem na carne vermelha o símbolo que ratifica o valor hierárquico, pois representa o Poder mais do que qualquer outro valor (TORRES, 2006).

Nesta sequência notou-se que o elo entre o cozinheiro e o açougueiro é carne, entregue frequentemente para ser preparada e servida aos hospedes no restaurante do hotel.

A convivência entre os personagens aflorou a atração sexual, não correspondida, de Dunga por Wellington Canibal. Dunga insinua seu desejo explicitando entre palavras e gestos a sua vontade.

Considerando-se o caráter de Poder da carne, neste caso, imputado à Wellington, o açougueiro, detentor da capacidade de dominar o outro, justificando o fascínio do cozinheiro o levando a subjugar-se aos dotes do açougueiro. 
Sequência 20 - O Nascimento do Amor

(Bar Avenida - int. - dia - cor - som direto)

Rabecão está num bar. Ele está sozinho numa mesa tomando uma cerveja. O quadro vai abrindo e podemos ver Lígia se aproximando da mesa. O bar está cheio de gente almoçando. Ela continua com a cara abusada. Rabecão se volta e lhe solta uma pequena risadinha, que Lígia não retribui. Coloca sobre a mesa mais uma garrafa de cerveja e se volta, e aí dá de cara com Isaac, que está arfando. Os dois se encaram por alguns instantes. Lígia vira o rosto e segue seu caminho de volta ao balcão. Isaac acompanha o movimento dela, num encantamento quase que hipnótico, e depois senta a mesa com Rabecão.

Rabecão (irônico): Gostou do material? Amarelo feito manga...

Isaac (espantado): Puta que me pariu, que mulher da porra! (se voltando para Rabecão) Quem é essa, Rabecão?

Rabecão (irônico): A loba do avenida, meu irmão. (se aproximando de Isaac) Essa mulher é muito doida. Parece puta, mas ninguém aqui comeu ela.

Para DaMatta (1986) é evidente a associação entre o ato sexual e ao ato de comer. Mulheres podem ser "comidas", porém a sociedade aceita que apenas após o cerimonial do casamento.

Isaac após abordar Ligia dá inicio a uma série de elogios os cabelos louros da moça "são ideais, puro barro, pura ideia". Remetendo a comparação da cor ao elemento terra, tido pela mitologia judaica como elemento de criação do homem (BATISTA, 2012).

Através do cinema as vivências transgressoras provocam a moral e os bons costumes, evocando o imaginário erótico. Na Grécia Antiga Eros e Afrodite eram os responsáveis por despertar ao Homem o desejo e a paixão. Em contrapartida, Dionísio, o deus da metamorfose e do sexo, simbolizava o irracional e os excessos. Desafiador e transgressor, ele personificava o deslumbramento despojado de culpa. (FELIZARDO, 2011).

Impulsionado pelos deuses da Grécia Antiga, especialmente por Dionísio, a explosão do desejo toma conta de Isaac quando conhece a intrigante Lígia, provocando sua libido. Imediatamente explicita a vontade de devorá-la. A cena ocorre em um ambiente público em meio a muitos fregueses almoçando. Como um primata, Isaac, instintivamente anuncia seu desejo de possuir a mulher que o atraiu, sem se preocupar com a exposição de seu ato. 
Sequência 24 - O Homem Perdido

(Bar da cidade - int. - dia - cor - som direto)

Isaac continua no avenida. Ele agora está visivelmente bêbado. Sobre sua mesa uma boa quantidade de garrafas está amontoada e ele bebe uma cachaça. Um prato está sujo de gordura e com alguns guardanapos sujos estão diante de si. O rádio toca uma música. Atrás de Isaac um casal dança desajeitadamente. Ele se volta para Lígia, elhe faz sinais, pedindo outra garrafa. Lígia, com sua costumeira cara de abuso pega uma cerveja para levar até Isaac. Coloca o casco sobre a mesa e abre violentamente, com um grande barulho. Isaac fica encarando-a, e ela lhe devolve a ousadia.

Isaac (bêbado): Todos os seus cabelos são dessa cor, ou a moça só tem dinheiro para pintar os da cabeça? (solta uma imensa gargalhada)

Lígia, sem nada dizer, sobe numa cadeira e depois numa mesa. Em seguida levanta sua saia. O público do bar começa a ovacionar a atitude dela, que, ainda encarando Isaac, abaixa a saia e desce da mesa...

Segundo Mucury (2011) Isaac ao comparar "todos" os cabelos de Lígia (ideias e barro) ofende grotescamente a moça com sua visão machista desmoralizando-a perante os presentes. O barro, vindo da terra transformou-se em ideias que são pensamentos livres e abstratos, produzindo uma espécie de sensação do avesso, do amordaçado, seduzindo e intrigando o predador.

O erotismo está para a sexualidade como a gastronomia está para a cozinha, assim afirmam vários livros sobre antropologia alimentar. Para o dito popular o verbo "comer" identifica a ação da alimentação e também do ato sexual. A gula e a luxuria estão no topo da lista dos pecados capitais. A sociedade funciona como reguladora dos pecados, especialmente procurando coibir o ato instintivo do ser humano (NASCIMENTO, 2007).

A exploração da sexualidade feminina pelo cinema transforma mulheres entre personagens "santas" (mulheres honradas, virgens, puras e comportadas); e "endiabradas" (femme fatales, governadas pela luxúria, dispostas a trazer o mal àqueles que arriscam a se atrair por elas) (FELIZARDO, 2011).

Isaac na condição de freguês havia escolhido o ser prato (Lígia). A dona do bar, ao ser desafiada, sobe à mesa e expõe sua genitália, como se com esta atitude informasse que o "prato escolhido" seria apreciado, porém não seria servido, uma vez que não estava disponível para degustação. O público presente aprovou a atitude de Lígia e entendeu o recado dado para Isaac. Os fregueses do 
bar, na condição de sociedade, expulsaram o homem que transgrediu os limites e tabus sociais.

\section{Sequência 32 - Em Torno da Fé}

(Becos de Favela e Igreja - ext. - tarde - cor - som direto)

Enquanto caminha por entre barracos e ruas estreitas de uma Favela, o Padre vai refletindo sobre a vida.

Padre em off: Na estrada em que você caminha podem faltar montanhas de coisas para satisfazer a vontade de um homem. Mas o homem é ímpio e a satisfação de um coração não faz parte de sua audácia. O homem é sexo e estômago.

Sócrates pensava que "os maus vivem para comer, enquanto as boas almas comem para viver". Foi a gula que roubou a ingenuidade de Adão e excluiu Eva do paraíso (NASCIMENTO, 2007).

Segundo Mucury (2011) a fala do padre esclarece a faceta como representação da união entre extremos. O sagrado e o profano, o alto e o baixo, o soberbo e o tênue, o ajuizado e o bronco, etc.

Lima et al (2001) publicaram que o anseio pela comida é exposto pela literatura como apetite, enquanto a fome recebe o sinônimo de desejo. O trinômio fome/apetite/desejo indica a semelhança entre os termos. O apetite em sentido amplo sinaliza o desejo por determinados alimentos. A dor no estômago provocada ausência prolongada de alimento, acarreta fraqueza, indisposição e tensão, provocando impaciência e ansiedade.

A manifestação do padre sobre o homem ser definido como "estômago e sexo" sugere a necessidade da satisfação plena do ser humano, buscando incessantemente seu equilíbrio entre os prazeres físico e espiritual. Tanto o sexo quanto o alimento tornam o homem um ser completo e satisfeito em sua maior e mais perfeita definição. A fome física e o desejo sexual se assemelham e estão intimamente pautadas ao carnal e espiritual.

\subsection{Expressão da antropofagia corrompendo a personalidade}

Após descobrir sobre a traição do marido, Kika resolve dar o flagrante

Sequência 50 - O Ataque da Onça

(Campo - ext. - noite - cor - som direto) 
Kika, que tem no rosto uma mistura de ódio e prazer, se levanta determinada e se aproxima do casal, que parecem dois animais no cio durante a cópula, e não se apercebem da aproximação de Kika, que pega uma pedra no chão. Quando ela está bem perto do casal mete a pedra na cabeça de Dayse que solta um grito. Assustado, Wellington se afasta com a calça à altura do joelho. Dayse cai sentada no chão e Kika avança sobre ela, mordendo-lhe a orelha. Dayse começa a gritar, tentando puxar o cabelo de Kika, mas não consegue. Com a calça ainda arriada, Wellington parte para o lado das duas, mas Kika, sem soltar Dayse, lhe dá um murro entre as pernas. Lentamente ele vai desmoronando.

Com Dayse já caída no chão, se debatendo, Kika, vitoriosa, se afasta. A cabeça de Dayse começa a se encher de sangue. Kika cospe de sua boca um pedaço de orelha ainda com o brinco. Depois cospe em cima....Outra lágrima escorre do rosto de Kika, só que desta vez ela está sorrindo, felicíssima...

O ato de comer pode ser definido como ação de tomar posse do que se quer, podendo ser o fígado ou a coragem do inimigo, bem como a carne da pessoa amada. Comer ou devorar pode traduzir o desejo onde o amor e o ódio co-habitam o mesmo espaço (NASCIMENTO, 2007).

Os índios tupis após as batalhas devoravam os bravos prisioneiros em cerimoniais de antropofagia. O caráter cultural dessas cerimônias tornava necessário capturar os guerreiros que seriam sacrificados. Corrobora dessa dinâmica o texto de Hans Staden, que três vezes foi levado á cerimônias antropofágicas e três vezes os índios se recusaram a comê-lo, porque chorava e se sujava, pedindo clemência. Não se comia um covarde, por se acreditar que herdaria sua personalidade (RIBEIRO, 2003).

Kika ao abocanhar e comer a orelha da amante do marido entra em processo de exacerbação e sai do confinamento. A mulher que até então era religiosa fervorosa e oprimida desaparece, e surge uma fêmea, devassa e sem pudor.

A traição do marido Wellington, curiosamente apelidado de Canibal, creditado a sua profissão, motivou a fúria de Kika que a partir de seu ato pode ser referida como Kika Canibal.

O processo antropofágico libertou a personagem da prisão física e espiritual. O pedaço de carne humana devorado personificou Kika libertando os seus sentimentos e instintos mais secretos, transformando-a em uma nova mulher. 
Sequência 57 - O Encontro dos Desesperados

(Rua da cidade - ext. - noite - cor - som direto)

O carro de Isaac caminha pela cidade, lentamente. A rua está muito escura e deserta. Ele cruza por uma mulher, Kika, com longos cabelos negros soltos, e um andar deprimido. A gola de sua camisa está suja de sangue. Isaac para o carro um pouco adiante dela. Numa decisão impensada, Kika se encosta na janela do carro e fica olhando atentamente para Isaac.

Isaac (meio sem interesse): Entre aí, minha filha!

Isaac: Isso aí na gola de seu pescoço é sangue?

Kika (muito séria): É. Acabei de comer a orelha da amante do meu marido (Risada e silêncio). Eu era uma mulher morta por dentro...

Os dois ficam um tempo em silêncio. De repente Kika começa a rir, e Isaac a acompanha. Ele agarra ela pelo pescoço e começa a lhe beijar violentamente. Kika, que num breve momento esboça uma reação, relaxa e se entrega com volúpia. Isaac se afasta dela.

Isaac: Vamos a um motel?

Kika (com escárnio): Vamos a todos os motéis.

Isaac dá uma arrancada no seu carro, e os dois desaparecem na escuridão da noite.

Os personagens de Amarelo Manga demonstram trágica subjetivamente em seu comportamento, levados a incorporar as degradações da alma, gerando um impecável perfil oculto monstruoso. Cidadãos comuns entre problemas e misérias, excluídos da sociedade nas grandes cidades. Homens e Mulheres são porta-vozes de um "apocalipse now", onde a degradação dos desejos e ansiedades são desgraçadamente exagerados (MUCURY, 2011).

Para Cavalcante (2005) o poder de Eros é imenso ao ponto de se autodestruir, expondo a faceta cruel e trágica do amor. Pode-se considerar o amor como manca do sofrimento. A qualidade do amor faz oposição ao promíscuo. O erotismo suplanta a adoração pelo ser desejado, evoluindo para a consagração dos instintos carnais.

O cinema explora uma fórmula chamada de "o retorno do reprimido", em que a dramatização extrapola os instintos primitivos de um personagem pela inaptidão de conter aquilo que estava dominado até o momento. Sua personalidade rompida o transforma-se em outro personagem (FELIZARDO, 2011).

A sequência denominada de "O encontro dos desesperados" marca a união entre dois personagens que sofreram o abandono. Ambos confusos, Kika 
libertada como fêmea e Isaac rejeitado como macho. Eles se entregam ao deus Eros que transformou a tragédia do amor em erotismo e sublimação.

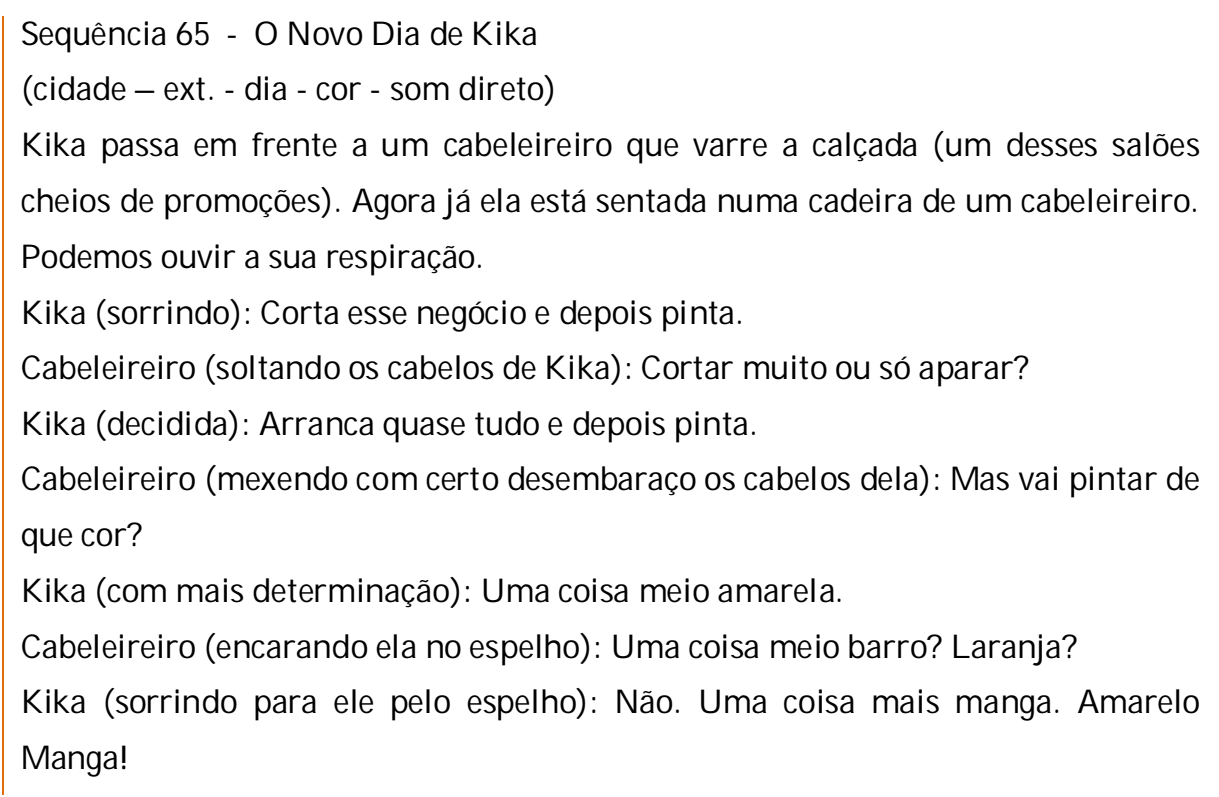

Kika concretiza sua mudança com um corte radical e mudança a cor de seus cabelos, que passaram de negro para amarelo, radicalizando e externando a mutação sofrida. A ex-religiosa teve seus valores invertidos, incorporando na cor amarelo manga de seus cabelos o extravasamento da catarse (MUCURY, 2011).

A simbologia do filme não apenas analisa a contraversão da cor amarelo do ouro, muito menos procura criticar o magnetismo do cinema nacional recente. Este amarelo é o amarelo das doenças, do exsudato, das purulências, da excreşão da cirrose, dos vermes (ALVES NETO, 2007).

Kika buscou a transformação da aparência como uma forma de esperança. A partir daí tornou-se uma nova mulher, exteriorizando seu interior, pois a fatalidade a libertou do confinamento da infelicidade.

\subsection{Degradação dos valores humanos evidenciado pelo abate de um boi}

Entre as sequências 25 e 26, no frigorífico, com som dramático, iniciouse inesperadamente o abate de um boi. $\mathrm{O}$ animal foi morto com estacas sendo marretadas em sua cabeça. Ainda agonizando foi arrastado e um punhal iniciou 
o corte em sua carcaça, desde o pescoço até a barriga. O sangue lavava o chão do abatedouro. A cena absolutamente chocante durou intermináveis 66 segundos.

Segundo Mucury (2011) a violência é notável durante o todo o firme, em intensidades diversas, mas segue em nuança até que ocorre o abate do boi. A cena é muito intensa e inusitada. Sob o som da banda Nação Zumbi a barbaridade deste ato, na verdade é um indício da ausência de ponderação sobre o abandono dos valores do homem. Os protagonistas do longa parecem distantes quando analisados sob o olhar da ficção, ademais a carne oferecida em todas as casas, é fruto da barbaridade apresentada.

A sequência em que um pastor vocifera um sermão, que parece infinito, e de modo repentino é cortada para o mergulho em um abatedouro com o piso tomado pelo sangue dos animais. Seria inevitável que o espectador se entregasse sem restrições àquele momento único e assim pode entender automaticamente as experiências, comparáveis ou não, para o entendimento da história (GONZAGA FILHO, 2011).

Dogmas influenciam as escolhas de nonges e sacerdotes, formando uma identidade social pautada pela escolha da comida. A abstinência pela carne possui forte relação com a preferência pela privação religiosa em detrimento ao Poder e a força. A negação ao consumo da carne simboliza a decisão pelo afastamento da sedução e do Poder, que torna o sacerdote redimido perante a vida simples escolhida, valorizando sua humildade pela disposição em alimentar-se com cereais e hortaliças (MANTOVANI, 2008).

No filme A Greve (1925) de Eisenstein mostrou uma das maiores sangrias cinematográficas, provocando o espectador, lembrando que o cinema na época era mudo, preto e branco, e escasso tecnicamente. A forma simbólica potencializou a mensagem como se passou o abate de um boi, paralelamente mostrada à repressão policial sobre os grevistas, chocando o público na ocasião (PEREIRA, 2001).

Segundo Torres (2006) sociólogos e antropólogos defendem que uma das razões da carne vermelha simbolizar hierarquia é a inegável aparência de sangue na comida. O sangue é uma imagem evidente da dominação humana.

O aspecto sagrado da carne enquanto alimento e suas preparações, muitas vezes seguidas de rituais para que ela possa ser comida, assim como, aspectos que a tornam não sagrada. Deste modo, comer carne assada, cozida, ou 
crua, possui antecedentes que a transformará em alimento para o corpo e para o espírito, ou simplesmente para a manutenção da vida (MASCARIN, 2005).

Amarelo Manga é o resumo da desordem. Todos os personagens e circunstâncias excederam os seus limites. Entre segredos e denúncias, revela os trágicos personagens abandonados por Deus. O filme não acaba. Não há conclusão. A vida mostra o lado avesso em retalhos de pessoas morta vivas (MUCURY, 2011).

A mensagem transmitida pela sequência do abate do boi evidenciou o pensamento do excepcional diretor Cláudio Assis, que inspirado em antológica referência do cinema mundial, utilizou o mesmo artifício para chamar a atenção do espectador que no caso de Amarelo Manga, pretendeu demonstrar a degradação dos valores humanos, conforme discorrido durante o desenvolvimento deste estudo.

Segundo a Mitologia Grega, a Lenda de Sísifo o denomina como um homem muito astucioso, porém inescrupuloso. Sua lenda pode ser contada em vários episódios de muita astúcia. Dentre os quais o afronte a Zeus o imputou o castigo de rolar uma enorme pedra até o cume de uma montanha, que mal chegando ao topo rolava de volta, devido seu enorme peso. O trabalho tinha de recomeçar, dia após dia, por toda a eternidade (GRIMAL, 2000).

A personagem Lígia foi porta-voz desta mensagem, iniciando e concluindo o longa-metragem com a mesma fala. No inicio (em off) e no final (afrontando a câmera): "As vezes fico imaginando de que forma as coisas acontecem. Primeiro vem um dia, e tudo acontece naquele dia até chegar a noite, que é a melhor parte. Mas logo depois vem o dia outra vez... e vai, vai, vai... é sem parar."

\section{Considerações Finais}

As expressões da comida nas cenas do filme envolvem os sentidos do prazer e sociabilidade. A comida associada à sexualidade gera satisfação. A antropofagia adultera a personalidade. E o abate de um boi simbolizou a degradação dos valores humanos.

Concluiu-se que o ponto central da análise deste trabalho esteve na importância da carne que permeou todas das expressões debatidas. Hora como 
alimento, hora como símbolo de Poder, sexo, e canibalismo. E por fim, a carne do boi abatido pôde levar a reflexão sobre a violência que o animal sofre antes de se tornar um alimento cotidiano.

Procurou-se contribuir com o debate aœerca da ciência da antropologia alimentar no campo das ciências humanas e sociais, associando esta discussão ao cinema como ferramenta de veiculação de cultura.

[का

\section{Bibliografia}

ALVES NETO, D. A narrativa simbólica do filme Amarelo manga: a composição da cor "amarelo manga". 2007. 33 f. Trabalho de Conclusão de Curso para Bacharel em Jornalismo - Faculdade de Ciências Sociais Aplicadas da UniCEUB - Centro Universitário de Brasília, Brasília, 2007.

AMARELO MANGA. Direção de Claudio Assis. Recife, 2003. 1DVD.

BATISTA F. F. O simbolismo da cor como característica de um espaço centrado na ideia do corpo em Amarelo Manga. 2012. 36 f. Trabalho de Conclusão de Curso de graduação em Produção Cultural - Universidade Federal Fluminense, Rio deJ aneiro, 2012.

BETTIOL, L. W; DIESEL, U. B. A gastronomia e a comunicação: análise do discurso gastronomia a partir do chef J amie Oliver e do filme Ratatouille. Univ. Arquitetura e Comunic. Social, Brasília, v. 8, n.1, p.113-156, jan/jun. 2011.

BORGES, S.S. Geografia e Cinema: Uma Representação Imaginária do Nordeste Brasileiro. V Encontro Sergipano de Educação Básica - ESEB. 03 a 05 de outubro de 2011.

CARNEIRO, H.F. Resenha do Filme A Comilança (1973) de Marco Ferreri, Revista Mal Estar e Subjetividade, Fortaleza, v.3, n.1, p.213-216, mar, 2003.

CAVALCANTE, M. I. Amor, Erotismo e Morte. Linguagem - Estudos e Pesquisas. Rev. UFG, Catalão, Goiás, v. 6, n. 1, p. 174-198, 2005.

COELHO, M. C. M. N. Cinema e Comida: projeção comentada de um percurso cinematográfico da alimentação e do cinema no contexto brasileiro. Seminário Cultura 
e Alimentação, SESC Vila Mariana. São Paulo. Outubro de 2006.

DAMATTA, R. O que faz o Brasil, Brasil? Rio de J aneiro. ROCCO, 1986. p.41-53.

FELIZARDO, C. K. Entre o prazer e o pudor: Representações do sexo e da sexualidade no cinema produzido no Rio Grande do Sul. 2011. 204 f. Dissertação de Pós-graduação da Faculdade de Comunicação Social - Faculdade Pontifícia Universidade Católica do Rio Grande do Sul, Porto Alegre, Rio Grande do Sul, 2011.

GALISA M. S. ET AL. Nutrição Conceitos e Aplicações. 1. ed. São Paulo: M.BOOKS, 2007. p. 258.

GONZAGA FILHO, B. M. Amarelo Manga: em projeções teóricas: três luzes sobre o filme dirigido por Cláudio Assis. 2011. 61 f. Dissertação de Mestrado em Estudos Literários - Universidade do Estado do Mato Grosso, Mato Grosso, 2011.

GRIMAL P. Dicionário da mitologia grega e romana. Pierre Gremal, tradução de Victor Jabouile. 4ed. Rio de Janeiro. Bertrand Brasil. BCD União de Editores S.A. 2000. p.422-423.

LIMA P.L.C. ET AL. Emergência e natureza da metáfora primária: Desejar é ter fome. Cad.Est.Ling. Campinas, SP, v.40, p. 107-140, Jan/jun. 2001.

LIRA, R. Rios, pontes e overdrives: trânsito e a (de) composição do espaço em Amarelo Manga. Crítica Cultural (Critic), Palhoça, SC, v.7, n.1, p.149-157, Jan/jun. 2012.

MASCARIN T. F. Algumas considerações a respeito da sacrilidade da carne e seu cotidiano. Congresso Internacional de História. Set-2011. p. 2870-2876, 2005.

MONTANARI, M. Comida como Cultura. Tradução de Letícia Martins de Andrade. Editora Senac São Paulo, São Paulo, 2008. p. 207.

MUCURY J. Bakhtin em Amarelo Manga. Rev. Água Viva. v.1, n.2. p.01-16. 2011.

NASCIMENTO, A. B. Comida: Prazeres, Gozos e Transgressões. 2. ed. rev. e ampl. Salvador: EDUFBA, 2007. p. 288.

PEREIRA, R.P. EISENSTEIN: O Cineasta da Revolução. Klepsidra: Revista virtual de historia, 2001 Disponível em: http://www.klepsidra.net/klepsidra9/ eisenstein.html. Acesso em 12 de outubro de 2013.

RIBEIRO, D. O povo brasileiro: a formação e o sentido do Brasil. São Paulo: Companhia das Letras. p.33-35, 2003. 
ROJAS, R. Do Panfletário ao Engajado: A influência de Eisenstein em Glauber Rocha a partir de uma análise intertextual de Terra em Transe. "Sociologia e Política em Tempos de Incerteza" Rev. Sociologia \& Política - I Seminário Nacional Sociologia \& Política UFPR, p.01-11, 2009.

ROLAND, A. M. A sociologia vê o cinema? Uma janela para ver as cores berrantes de Amarelo Manga. Ten Mund. Fortaleza, v. 4, n. 6, jan/jul, 2008.

SANTOS, C. R. A. A alimentação e seu lugar na história: os tempos da memória gustativa. Editora UFPR. História, Questões \& Debates. Curutiba n. 42, p-11-31, 2005.

SANTOS, P. R. As Relações de Poder em Amarelo Manga e Seus Espectadores. Intercom - Sociedade Brasileira de Estudos Interdisciplinares da Comunicação. XI Congresso de Ciências na Região Sul. Novo Hamburgo, RS, 17a 19 de maio de 2010.

TORRES C.V. ET AL. Consumo no Brasil: um teste etic da relação entre valores humanos, significados do produto e preferência de consumo em culturas coletivas. Rev. Psicologia. V.6, n.1, jan-jun, p. 79-105. 2006. 